\section{Reading the tablets}

A NEW kit for identifying unlabelled drugs, recently introduced onto the British market, should prove a useful tool not only for those involved in identifying drugs but also for the pharmaceutical companies that produce them. The system, called Tablident, provides a method of matching up the thousands of unlabelled drugs, marked or unmarked, brought to hospital staff, pharmacists, the police and custom and excise officers for identification.

The system comes in two parts. The first

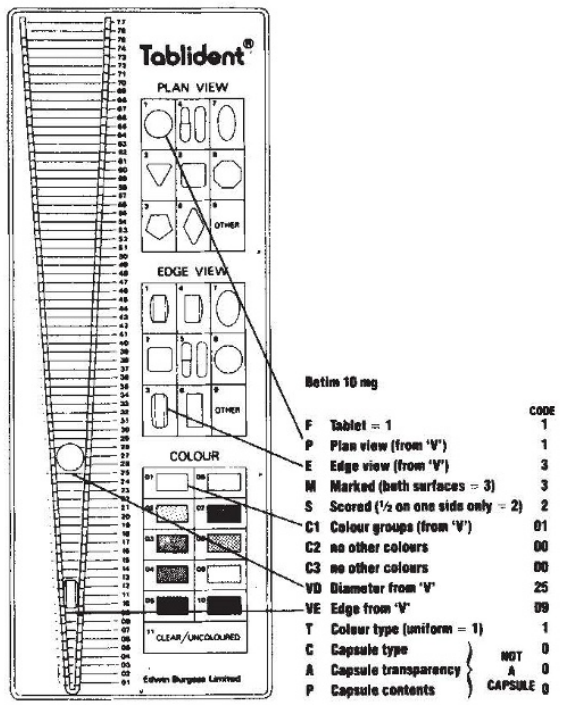

is an ingenious gadget for measuring the diameter and depth of the tablet. The idea for the machine came from a range-finder used by pilots of Second World War aircraft that its inventor, Dr Stephen Thomas, found in a junk shop. It consists of the $\mathrm{V}$-shaped slot shown in the picture into which the pill is dropped. The dimensions and characteristics of the pill are read off as a 19-digit code which provides a binary "fingerprint" for the pill.

But it is the second part of the Tablident that is the system's key to success. This is a comprehensive computer readout against which the binary code is matched. The data bank lists the name, active ingredient, manufacturer's name and address and the legal class of 2,500 drugs. Because around 15-20 per cent of the products change between editions, the list is updated every 3 months.

The system's manufacturers, Edwin Burgess, claim that 90 per cent of pills on the British market can be identified precisely with Tablident, and the choice in 98 per cent of cases can be narrowed down to one in three. But this is considered a conservative estimate by users of the system, such as Dr John Henry of the National Poisons Information Service, who says that in a clinical situation the drug can be correctly identified in nearly all cases, provided the tablet is listed in the data bank.

But therein lies the rub. At present,
Tablident lists only 2,500 tablets and, although the exact number of drugs on the market is not known, the Department of Health and Social Security had issued more than 7,000 licences to produce solid-form drugs in the United Kingdom by early 1983 , of which about 4,000-6,000 are probably in general use. Therefore, although Tablident may offer a more comprehensive identification system than is otherwise available through IMPREX, the MIMS Colour Index and the Chemist and Druggist Directory, it is far from being comprehensive.

The problem of providing a complete identification kit is made worse when applications outside the National Health Service are taken into account. For use in customs and excise, an international directory would be needed. Although large drug companies such as Ciba-Geigy operate an approximate standardizing policy within individual countries, so that no two pills produced there are identical, the same drug may be produced in different forms in different countries. Despite such problems, however, it is planned to extend the Tablident data bank to include the United States, Canada, West Germany and Scandinavia. But with about 30,000 different tablets in circulation in West Germany alone, it could be a long time before the system comes into general use.

Melanie Kee

\title{
Czechoslovak education
}

\section{Catching up on science}

SCIENCE teachers in Czechoslovakia still have to face "important tasks"' according to $\mathrm{Mr}$ Milan Vondruska, Minister of Education of the Czech Republic. In particular, he say, syllabuses from kindergarten to university need to be adjusted to ensure the consistent introduction of science into "all aspects of school activities"'.

Concern with science in Czechoslovakia is not new. The educational reforms of 1976, which introduced universal 10-year education, stressed that this should be of "general polytechnical type" with special emphasis on mathematics and the natural sciences, particularly in secondary vocational schools. The coming academic year will mark the completion of the 1976 reforms, and a review of the new system has, it appears, been quietly going forward in both Czech and Slovak Republics.

Since education in Czechoslovakia is closely geared to the needs of the national economy, it appears that the present 10 years of compulsory polytechnic education (8 primary, 2 secondary) is not producing a sufficient number of skilled workers. A high-level committe of the Slovak National Council recently called for more pupils to be admitted to the final 2 (noncompulsory) years. $\mathrm{Mr}$ Vondruska seemed to relate the need for more science with the training of future workers. Side by side with science, he said, should go " $a$ familiarization with the labour of manual workers", which must "penetrate the content of socialist education", especially at the primary levels. This linking of science with work education reflects a specifically Czech contribution to the theory of the "scientific-technical revolution" which features often in the directives of centrally planned socialist economies.

In Czechoslovakia, at least, this phrase is something more than a slogan for swifter and faster mechanization and automation. In the early 1960s, a Czech philosopher, Dr Radovan Richter, worked out the theor- etical implications for Marxism of such a revolution in which "science" would replace "labour" as the productive force. In doing so, Dr Richter sowed many of the ideological seeds which led to the Prague spring, but, unlike the other philosophers associated with that attempt at reform, he came unscathed through the purges of 1969-70, and was even promoted to a leading post at the Sociological and Philosophical Institute at the Czechoslovak Academy of Sciences.

Whatever the background in political theory, however, Mr Vondruska's emphasis on more science seems to reflect a real concern of the economic planners about the slow rate of industrial implementation

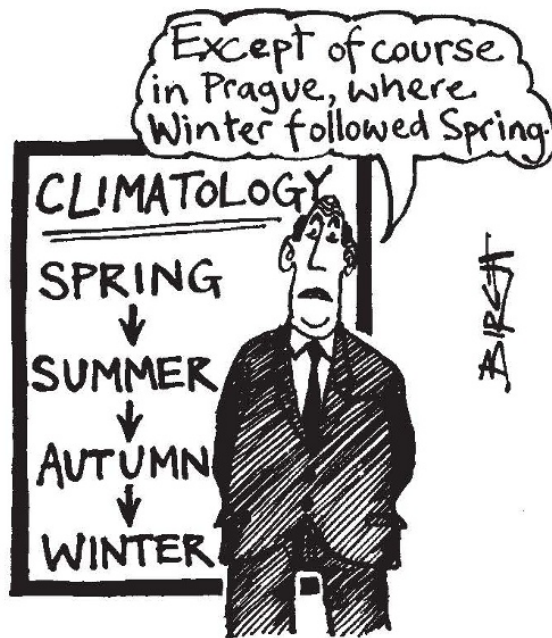

of new technologies and research results. Earlier this year, there were high-level denials of a shortage of research funding, and the blame was attributed to bad planning and misunderstanding, at the factory management level, of what the scientists and technologists have to offer. If this is a correct diagnosis, then Mr Vondruska's "adjusted" syllabuses could well be the answer. If, however, it is necessary to begin at the kindergarten level, the full effect is unlikely to be feit this century. Vera Rich 